\title{
A AVALIAÇÃo NO ÂMBITO do Pacto Nacional pela Alfabetização na IdAde CERTA
}

Hilda Aparecida Linhares da Silva Micarello ${ }^{1}$

Resumo

Neste artigo é abordada a avaliação no âmbito do Pacto Nacional pela Alfabetização na Idade Certa. Na primeira seção do texto são discutidas as orientações sobre a avaliação interna à escola, oferecidas pelos materiais de formação do Pacto, com ênfase na dimensão processual e no necessário envolvimento dos diferentes atores da cena educacional com as práticas avaliativas. $\mathrm{Na}$ segunda seção é abordada a avaliação externa à escola, a Avaliação Nacional da Alfabetização - ANA - instituída como parte das ações do Pacto. São apresentados os princípios que fundamentam essa avaliação, os instrumentos utilizados para efetivá-la e seus limites e possibilidades. $\mathrm{O}$ conceito de validade dos testes utilizados em avaliações em larga escala é problematizado nessa segunda seção, buscando-se ampliá-lo para se pensar, para além da validade psicométrica, a validade de realização da própria avaliação, diretamente relacionada aos modos de apropriação de seus resultados.

Palavras-chave: Alfabetização. Avaliação. PNAIC.

\section{INTRODUÇÃO}

Certamente alguns de nós fomos alunos e/ou professores da escola pública numa época na qual os alunos da

1 Professora Adjunta da Faculdade de Educação, da Universidade Federal de Juiz de Fora/UFJF. Doutora em Educação pela PUC-Rio. 
$1^{\mathrm{a}}$ série do antigo $1^{\mathrm{o}}$ grau eram chamados à sala da diretora ou da coordenadora da escola para serem avaliados em leitura. Nessas ocasiões era apresentado aos alunos algum texto, em geral do livro didático, que eles deveriam ler "de carreirinha”, sem tropeçar ou escandir sílabas. Aquele momento era vivido com ansiedade por professores e alunos, pois ambos sabiam que estavam sendo avaliados e que os resultados daquela avaliação traria consequências para a vida escolar dos estudantes. Aqueles que tivessem bom desempenho ocupariam, no ano seguinte, as melhores turmas, as turmas A ou B, para as quais eram destinados também os professores com mais experiência. Aqueles que apresentassem uma leitura ainda insegura muito provavelmente ficariam nas turmas C, D E... Os que não conseguissem realizar a tarefa teriam que repetir o ano, engrossando as estatísticas de reprovação na $1^{\text {a }}$ série, um problema histórico no Brasil.

Esse passado não muito distante remonta a um tempo no qual a alfabetização era concebida como uma atividade mecânica de codificação/decodificação do escrito, e o conhecimento matemático identificado com a reprodução de modelos. Nessa perspectiva a leitura em voz alta e o ditado eram os instrumentos privilegiados para se aferir se uma criança tinha ou não logrado êxito no seu processo de alfabetização. $\mathrm{Na}$ matemática as continhas (arme e efetue) e os problemas (que deveriam ser resolvidos utilizandose o esquema sentença matemática, cálculo e resposta) eram as tarefas a partir das quais os estudantes deveriam demonstrar seus conhecimentos. Tais práticas, ancoradas numa concepção de avaliação como "julgamento de valor dos resultados alcançados” (HOFFMANN, 2005, p. 14) reduzem o ato de avaliar a uma perspectiva sentenciadora, que pouco contribui para se pensar o processo educacional. Em geral o resultado desse modelo de avaliação é um veredito - aprovado ou reprovado - que, quando se trata da alfabetização, significa ter que refazer todo o processo desde o seu início, sem que os avanços alcançados pelo alfabetizando em termos de seus conhecimentos sobre a língua escrita ao longo de um ano de trabalho sejam considerados. 
Decorre dessa perspectiva uma "dicotomia entre educação e avaliação” (HOFFMANN, 2005, p. 14) que obscurece um princípio fundamental da ação avaliativa: o de oferecer diagnósticos capazes de informar a reorganização da prática educativa no sentido de que ela possa contribuir, de forma mais efetiva, com a promoção dos educandos.

Numa concepção de alfabetização como processo discursivo, que é aquela que vem orientando as atuais políticas de alfabetização no Brasil, dentre elas o Pacto Nacional pela Alfabetização na Idade Certa - PNAIC, os alfabetizandos devem ser envolvidos em práticas reais de leitura e escrita, para as quais produzam sentido, ao mesmo tempo em que se apropriam das relações grafofônicas que organizam o sistema de escrita. Nessa concepção a avaliação tem o papel de oferecer ao professor, às escolas e aos sistemas de ensino, diagnósticos sobre como os alunos estão vivenciando os processos de apropriação do sistema de representação e, ao mesmo tempo, seu envolvimento com diferentes práticas de leitura e de escrita. Tais vivências não são apreensíveis por um único instrumento de avaliação. São necessários vários instrumentos e procedimentos que possam ser apropriados pelos docentes, pelas escolas e sistemas de ensino na organização de seu planejamento e que permitam uma continuidade das práticas alfabetizadoras ao longo dos três anos de escolarização que constituem o bloco pedagógico ${ }^{2}$. Nesse sentido, a avaliação é um instrumento fundamental para o monitoramento de metas educacionais, sejam aquelas estabelecidas pelo professor em relação aos seus alunos, sejam as definidas no âmbito dos sistemas de ensino em relação a uma população mais ampla - de um município, de um estado, do país.

\footnotetext{
O bloco pedagógico está previsto nas Diretrizes Curriculares Nacionais para o Ensino Fundamental de nove anos. No artigo 30 dessas Diretrizes, $\mathbb{\$} 1^{\circ}$ lêse que: " $\mathbb{S} 1^{\circ}$ Mesmo quando o sistema de ensino ou a escola, no uso de sua autonomia, fizerem opção pelo regime seriado, será necessário considerar os três anos iniciais do Ensino Fundamental como um bloco pedagógico ou um ciclo sequencial não passível de interrupção, voltado para ampliar a todos os alunos as oportunidades de sistematização e aprofundamento das aprendizagens básicas, imprescindíveis para o prosseguimento dos estudos.” (BRASIL, MCE/CNE/CEB, 2010).
}

A avaliaçao no âmbito do Pacto Nacional pela Alfabetização na Idade Certa 
Considerando a centralidade da avaliação num processo orientado para o alcance de metas, como a alfabetização, o objetivo deste artigo é discutir como ela está contemplada nas ações do Pacto Nacional pela Alfabetização na Idade Certa. O Pacto é uma política nacional que congrega esforços da União, do governo do Distrito Federal, dos estados e municípios em torno da meta de que todas as crianças brasileiras estejam alfabetizadas até os 8 anos de idade. Dado seu alcance e impacto, é importante compreender, para além das práticas de avaliação propostas aos professores alfabetizadores, como é avaliada a própria política e seu alcance. Neste texto são abordadas a avaliação interna à escola, que é aquela realizada pelos professores e a partir da qual produzem-se diagnósticos sobre cada um dos alunos ao longo de seu processo de alfabetização, e a avaliação externa à escola, em larga escala, que oferece diagnósticos das escolas e dos sistemas de ensino e que focaliza as aprendizagens alcançadas ao término do processo.

Inicialmente apresento algumas considerações sobre as orientações, oferecidas pelos materiais de formação do Pacto, relativas à avaliação interna à escola. Essa avaliação não deve se restringir aos aspectos cognitivos envolvidos nos processos de aprendizagem, mas diz respeito também aos modos como os estudantes constroem suas subjetividades a partir das relações que estabelecem com os objetos do conhecimento. Envolve, pois, as relações dos estudantes com o saber (CHARLOT, 2000), mediadas por outros sujeitos - seus pares, os professores, as famílias.

O objetivo da primeira seção deste texto é o de refletir sobre como as orientações sobre a avaliação, presentes nos documentos de formação do Pacto, podem contribuir para que os professores e as escolas encaminhem a prática avaliativa de forma mais abrangente, beneficiando-se dos resultados dessas avaliações na organização de um planejamento que favoreça o tratamento do bloco pedagógico na perspectiva de um contínuo ao longo do qual se dá a alfabetização. Tal perspectiva é uma condição necessária ao alcance das metas previstas para os três primeiros anos de escolarização. 
Em seguida, discuto os princípios e forma de organização da ANA - Avaliação Nacional da Alfabetização, como esses princípios podem ser compreendidos no contexto mais amplo do debate sobre a avaliação e seu papel na promoção da equidade, os requisitos de validade que devem orientar a elaboração dos testes que compõem as avaliações em larga escala e como esses requisitos podem ser interpretados no caso de uma avaliação em larga escala da alfabetização.

Finalmente lanço algumas questões a serem consideradas pelos professores, pelas escolas e pelos sistemas de ensino a partir das considerações formuladas nos tópicos anteriores.

\section{A proposta de AVAliaÇÃo DO CURRÍCUlO NOS DOCUMENTOS DO PACTO DESTINADOS À FORMAÇÃO DE PROFESSORES}

A avaliação no ciclo de alfabetização é abordada pelos documentos de formação do Pacto no caderno intitulado "Avaliação no ciclo de alfabetização: reflexões e sugestões" (BRASIL, 2012). Neste caderno é anunciada a concepção de avaliação que subsidia as ações do Pacto, identificando tal concepção com uma perspectiva mais progressista de avaliação

(...) que a compreende como processos, desenvolvimentos, percursos de formação e que se efetiva do início ao fim da escolarização. Ao se adotar uma concepção mais progressista, pode-se considerar a avaliação como uma ação que inclui os vários sujeitos, ou seja, como uma ação intencional que se dá de modo multidirecional. Dessa forma, o que se busca é um sistema integrado de co-avaliação, no qual docentes, discentes e equipes de profissionais da escola e de outros sistemas avaliam e são avaliados. (p. 07).

Uma decorrência importante da perspectiva de avaliação anunciada é a ideia de avaliação processual, que se dá
A avaliação no âmbito do Pacto Nacional pela Alfabetização na Idade Certa 
durante todas as etapas do processo de alfabetização. Essas etapas se referem não apenas ao recorte temporal de cada ano de escolarização, mas são vivenciadas ao longo dos três anos que compõem o bloco pedagógico. Nesse sentido a avaliação do currículo, que é aquela que os professores realizam em suas salas de aula e que deve abranger todas as dimensões envolvidas nos processo de alfabetização e letramento dos estudantes, deve oferecer subsídios para o planejamento das intervenções pedagógicas ao longo de cada ano, na transição entre os anos e na passagem às etapas posteriores de escolarização.

A concepção de uma avaliação processual é especialmente importante, no caso da alfabetização, para que os percursos individuais de aprendizagem dos estudantes sejam considerados na abordagem do currículo. Tal perspectiva busca romper com práticas instituídas, e muitas vezes arraigadas à cultura das escolas e dos docentes, de utilizar a avaliação para estabelecer comparações entre os alunos, sem considerar os esforços empreendidos por cada um deles em seu caminhar em direção ao desempenho desejado. Muitas vezes um estudante, embora ainda não tenha desenvolvido as habilidades previstas para a etapa de escolarização em que se encontra, demonstra estar em processo de desenvolvimento dessas habilidades, necessitando, para consolidá-las, de algumas intervenções focalizadas em suas dificuldades e potencialidades específicas. Uma avaliação processual contribui para que se definam quais seriam as melhores intervenções direcionadas à turma, como um todo, e aquelas que devem ser direcionadas especificamente a um estudante ou grupo de estudantes ao longo do processo. Quando se trata da alfabetização, em especial, essas intervenções são necessárias para que se reduzam as taxas de reprovação ainda percebidas ao término do $3^{\circ}$ e ou $4^{\circ}$ ano de escolarização, quando muitos estudantes são retidos por não terem atingido os níveis de alfabetismo considerados necessários à continuidade de seu processo de escolarização. Uma abordagem processual da avaliação a destitui do caráter sentenciador, que muitas vezes ela tem 
assumido, para colocá-la a serviço da promoção dos sujeitos, de seu desenvolvimento, considerando os diferentes ritmos em que tal desenvolvimento pode se dar.

Quanto ao envolvimento dos vários atores com a prática avaliativa, quando se trata de uma política com o alcance e os objetivos do Pacto, que prevê uma ação integrada entre várias instâncias responsáveis pela educação no país, esta perspectiva integradora traz também a ideia de co-responsabilização dos atores com o êxito do processo. Essa perspectiva rompe com a tendência de identificar a avaliação como uma responsabilidade exclusiva do professor. A ideia de um "sistema integrado de co-avaliação" introduz nesse debate outros atores - os alunos, a gestão escolar e a gestão dos sistemas - permitindo perspectivar a avaliação como instrumento para diagnosticar não apenas as aprendizagens realizadas pelos educandos, mas também as condições de oferta da educação: as práticas pedagógicas e os fatores contextuais que interferem nessas práticas, além das percepções dos sujeitos sobre o ato avaliativo. Assim a avaliação passa a ser uma prática que extrapola o contexto restrito à sala de aula e permite compreender as responsabilidades de todos os atores envolvidos no processo educacional com a promoção dos estudantes e de suas aprendizagens.

No que concerne às sugestões aos docentes sobre como encaminhar a avaliação em suas atividades cotidianas são contemplados, pelos cadernos de formação, diferentes eixos a partir dos quais se organizam as orientações dos documentos do Pacto sobre o processo de alfabetização. Esses eixos são: leitura, escrita (produção textual), oralidade, apropriação do sistema de escrita alfabético e ortografia. Para cada eixo são propostos instrumentos e práticas de avaliação específicos, considerando as peculiaridades do eixo e as possibilidades de apreender os progressos alcançados pelos estudantes ao longo do processo de alfabetização. A abordagem dos aspectos a serem avaliados se faz em termos de habilidades previstas para cada ano do bloco pedagógico.
A avaliação no âmbito do Pacto Nacional pela Alfabetização na Idade Certa 
A organização dos instrumentos e procedimentos de avaliação a partir dos eixos e o tratamento das componentes curriculares a partir de habilidades a serem desenvolvidas pelos estudantes contribuem para que os docentes percebam o caráter multifacetado dos processos de alfabetização e letramento. Essa abordagem é importante, pois permite que se percebam os aspectos de cada eixo que devem ser objeto de intervenções sistemáticas dos docentes, que nem sempre têm clareza sobre esses aspectos.

É comum que os professores reconheçam, por exemplo, a importância da oralidade para o desenvolvimento da leitura e da escrita. Entretanto, nem sempre eles são capazes de apontar quais são as habilidades envolvidas nas práticas de oralidade que devem ser trabalhadas com os alunos ao longo da alfabetização, e mesmo em etapas posteriores do processo de escolarização. Ao apresentar algumas dimensões envolvidas nas práticas de oralidade - "valorização de textos escritos de tradição oral; oralização do texto escrito; variação linguística e relações entre fala e escrita; produção e compreensão de gêneros orais" (BRASIL, 2012, p. 35), que devem ser objeto de observação e registro pelos docentes, sugerindo atividades a partir das quais essas dimensões podem ser observadas, o documento contribui para que os professores possam, intencionalmente, propor situações que promovam o desenvolvimento das habilidades relacionadas a cada eixo.

O mesmo pode ser dito sobre as relações entre leitura, escrita e apropriação do sistema de escrita alfabético. O reconhecimento dessas relações e sua abordagem sistemática pelos alfabetizadores são necessários para que os estudantes possam adquirir fluência e autonomia, tanto na leitura quanto na escrita. O que acontece é que, em geral, os docentes sentem-se pouco preparados para explorar as relações entre a pauta sonora e a escrita e, consequentemente, para observar como os estudantes estão construindo essas relações. Ao descrever as capacidades envolvidas no processo de apropriação do sistema de escrita alfabético, o documento contribui para que os docentes possam 
observar se e como os estudantes e encontram em relação a essas capacidades.

Sem desconsiderar a relevância da forma de organização das orientações sobre avaliação oferecidas pelos documentos do Pacto, cumpre destacar que as habilidades, discriminadas para fins de avaliação, se desenvolvem num contexto no qual outros fatores também são determinantes para o êxito do processo de ensino e aprendizagem. Nesse sentido, Hoffmann (2007) esclarece: "A relação educador/educando exige o processo avaliativo mediador, que, por sua vez, só sobrevive por meio do resgate à sensibilidade, do respeito ao outro, da convivência e de procedimentos dialógicos e significativos" (p. 15). A autora alerta ser um erro reduzir a avaliação a processos objetivos, pois o ato avaliativo envolve pessoas que têm modos peculiares de ver o mundo e de se expressarem sobre ele. Assim, embora seja importante a clareza sobre cada um dos aspectos que devem orientar a observação e o acompanhamento das aprendizagens, é igualmente importante considerar as mediações que se dão entre os estudantes e os objetos de aprendizagem, e também entre os sujeitos envolvidos no ato de avaliar, educadores e educandos. Essas mediações são parte integrante e fundamental dos processos de alfabetização e letramento dos estudantes, uma vez que, a partir delas, se estabelece um determinado tipo de relação entre o alfabetizando, a leitura, a escrita e a matemática que se reflete no interesse e envolvimento dos estudantes com a língua escrita e os conhecimentos matemáticos.

\section{A AVAliaÇÃo EM LARGA ESCALA DA ALFABETIZAÇÃO NO CONTEXTO DO PACTO Nacional PEla Alfabetização NA IdAde Certa: a $\mathrm{ANA}^{3}$}

As avaliações em larga escala têm sido, nos últimos anos, alvo de intensos debates, uma vez que trazem à cena

A Avaliação Nacional da Alfabetização - ANA - é uma das ações previstas na portaria que institui o Pacto Nacional pela Alfabetização na Idade Certa.
A avaliação no âmbito do Pacto Nacional pela Alfabetização na Idade Certa 
educacional o tema das responsabilidades de professores, gestores e dos sistemas com a melhoria da qualidade da educação e com a prestação de contas públicas acerca das ações em prol dessa melhoria. Embora fuja aos objetivos deste texto aprofundar esses debates, é importante destacar que eles necessitam ser aprofundados com base em estudos e pesquisas que permitam travá-los de modo menos apaixonado e mais informado, para que se possa melhor dimensionar as possibilidades e limites das avaliações em larga escala. São necessários estudos que visem aprofundar os conhecimentos acerca dos impactos dessas avaliações no cotidiano das escolas e na vida dos professores e gestores, dos modos de apropriação dos seus resultados pelos sistemas de ensino e da pertinência e efetividade dos instrumentos por elas utilizados para diagnosticar as aprendizagens realizadas pelos estudantes. Antônio Nóvoa (2009), em apresentação à obra de Domingos Fernandes sobre o tema da avaliação, alerta:

Há importantes mudanças internas nas escolas, sobretudo na capacidade de entender os juízos e os vereditos proferidos pelos professores, não apenas como "sanções", mas, sobretudo como fatores de aperfeiçoamento. Mas há também consequências externas dos processos de avaliação, nomeadamente no que diz respeito à regulação das escolas e do sistema educacional. Neste sentido, é preciso sublinhar a dimensão pedagógica da avaliação, mas também seu papel como elo entre a escola e a sociedade. O esforço de comunicação pública do trabalho escolar passa, em grande medida, por uma utilização inteligente de instrumentos e resultados da avaliação (p. 15-16).

O objetivo desta seção é justamente o de trazer algumas reflexões sobre os instrumentos utilizados pela ANA e sobre as possibilidades de apropriação de seus resultados

Esta ação é descrita no artigo $9^{\circ}$, inciso IV da referida portaria, a qual prevê a realização de "avaliação externa universal do nível de alfabetização ao final do $3^{\circ}$ ano do ensino fundamental, aplicada pelo Inep" (art. $9^{\circ}$, inciso IV). A ANA foi integrada ao SAEB - Sistema de Avaliação da Educação Básica - pela portaria 482 de 7 de junho de 2013. 
para que essa avaliação possa alcançar o objetivo a que se propõe. Esse objetivo é anunciado no documento base elaborado pelo Inep com o intuito de tornar pública a estrutura dessa avaliação nacional: produzir "indicadores que contribuam para a melhoria do processo de alfabetização nas escolas públicas brasileiras” (BRASIL/ INEP, 2013).

Um primeiro aspecto a ser considerado nesse processo de melhoria é que ela não passa apenas por mudanças nas práticas pedagógicas, mas requer um olhar atento às condições de oferta da educação. Nesse sentido, é importante lembrar que a ANA não se restringe à aplicação de testes cognitivos aos estudantes, embora seja essa dimensão da avaliação que maior impacto traz ao contexto escolar e também a que mais mobiliza as escolas e os docentes. Compõem a ANA, além de testes cognitivos de Língua Portuguesa (leitura e escrita) e de Matemática, questionários contextuais que visam aferir aspectos relacionados às condições de oferta da educação: "condições de infraestrutura, formação de professores, gestão da unidade escolar, organização do trabalho pedagógico, entre outras" (BRASIL/INEP, 2013, p. 8). Assim, um primeiro desafio que se impõe ao processo de divulgação e apropriação dos resultados da Avaliação Nacional da Alfabetização é o de articular esses instrumentos - testes cognitivos e questionários contextuais - na produção de um diagnóstico que englobe esses diferentes aspectos que impactam a qualidade da educação. Esse é um desafio importante, uma vez que são ainda poucos os estudos que busquem articular os fatores contextuais ao desempenho dos estudantes, sendo essa frágil articulação um dos fatores que contribuem para uma exclusiva responsabilização dos professores pelos resultados alcançados pelos estudantes.

Franco (2004), ao refletir sobre o papel dos questionários contextuais na produção de medidas educacionais destaca: "Como a avaliação envolve o estabelecimento de uma complexa rede de relações entre construtos, não avaliação sem boas medidas sobre as escolas, seus professores, direção e corpo discente” (p. 49).
A avaliação no âmbito do Pacto Nacional pela Alfabetização na Idade Certa 
Outra dimensão a ser considerada quando se trata da utilização dos resultados das avaliações em larga escala é a necessária construção de uma série histórica que permita acompanhar, ao longo do tempo, as mudanças ocorridas, tanto nas condições de oferta quanto no desempenho dos estudantes nos testes. No caso específico da ANA tal necessidade é ainda mais relevante, uma vez que a aplicação dessa avaliação ao longo de vários anos permitirá dimensionar possíveis impactos que a formação de professores no âmbito do Pacto Nacional pela Alfabetização na Idade Certa possam trazer ao desempenho dos estudantes concluintes do $3^{\circ}$ ano do ensino fundamental. No ano de 2013 a ANA foi aplicada pela primeira vez aos estudantes concluintes do $3^{\circ}$ ano do ensino fundamental. Nesse ano as ações do Pacto apenas haviam se iniciado e, ainda assim, de forma muito heterogênea quanto à data de seu início nos diferentes estados e municípios brasileiros que aderiram ao Pacto. Desse modo, em sua primeira edição a ANA pode ter contribuído para se constituir uma "linha de base" que servirá de um primeiro diagnóstico dos níveis de alfabetização dos estudantes em Língua Portuguesa e Matemática e das condições de oferta da educação pelas escolas e sistemas de ensino que possa servir de parâmetro para um acompanhamento das mudanças ao longo dos anos.

Também nesse caso a articulação entre os resultados dos testes cognitivos e os questionários contextuais se mostra fundamental. A formação de professores, uma das ações do Pacto, tem sido acompanhada por mudanças qualitativas nas condições de oferta pelos sistemas e pelas escolas, tais como: adequadas condições da rede física, disponibilidade de materiais e de pessoal de apoio ao trabalho docente? Quais estruturas são criadas para o apoio pedagógico aos professores em seus contextos de atuação? Como tem se dado a articulação entre os três anos do bloco pedagógico? Como as famílias têm sido envolvidas pelas escolas nos processos de aprendizagem dos estudantes? Essas, dentre outras questões, só podem ser 
compreendidas se forem considerados os dados produzidos pelos questionários contextuais, respondidos por gestores e professores.

No que concerne especificamente aos testes cognitivos de Língua Portuguesa e Matemática, na primeira versão da ANA, aplicada no ano de 2013, os alunos foram divididos igualmente em dois grupos: metade dos estudantes avaliados realizaram testes de Língua Portuguesa, compostos por 17 questões de múltipla escolha de leitura e 3 questões abertas, de produção escrita. A outra metade respondeu ao teste composto por 20 questões de Matemática. Assim, embora a avaliação tenha sido universal, por ter sido realizada por todos os estudantes brasileiros concluintes do $3^{\circ}$ ano do ensino fundamental, no que se refere às componentes curriculares de Língua Portuguesa e Matemática ela assumiu um caráter amostral, uma vez que apenas metade dos estudantes realizaram testes dessas disciplinas. Isso não invalida a consistência dos resultados obtidos, uma vez que a amostra para ambas as disciplinas foi amplamente representativa da realidade brasileira.

Os itens que compõem as avaliações em larga escala são produzidos com base em matrizes de referência, nas quais são descritas as habilidades que se pretende avaliar no teste. Dados os limites de uma avaliação em larga escala, as habilidades que compõem uma matriz de referência são aquelas passíveis de se avaliar em testes de múltipla escolha ou a partir de questões abertas também adequadas a este tipo de avaliação. Por essa razão essas matrizes não podem ser tomadas como o currículo, sendo este um dos perigos a serem evitados quando se trata de avaliações em larga escala. Outras tantas habilidades que não estão descritas nas matrizes, mas que concorrem para o desenvolvimento daquelas que ali estão, devem ser trabalhadas pelos docentes em seu cotidiano com os estudantes.

No caso de Língua Portuguesa, as habilidades descritas no Eixo Leitura da matriz de referência da ANA envolvem a leitura de palavras (duas primeiras habilidades da matriz) e a leitura com compreensão de textos de diferentes gêneros
A avaliação no âmbito do Pacto Nacional pela Alfabetização na Idade Certa 
(as demais habilidades do Eixo Leitura da referida matriz). Tal compreensão se refere não apenas a informações que podem ser encontradas na superfície textual, mas também à realização de inferências a partir da conjugação de diferentes pistas textuais e do estabelecimento de relações entre partes do texto.

Quanto ao Eixo Escrita, são avaliadas a grafia de palavras compostas por correspondências regulares diretas entre grafemas e fonemas; a grafia de palavras compostas por correspondências regulares contextuais entre letras ou grupos de letras e seu valor sonoro; e a produção de textos adequados a uma determinada situação comunicativa. Essas habilidades referem-se ao domínio da base alfabética pelos estudantes e ao uso de algumas regras ortográficas mais elementares para produzir textos que atendam a uma função social determinada.

O teste da ANA não prevê a mediação de um aplicador que leia os enunciados dos itens de leitura, escrita ou matemática. Estes enunciados devem ser lidos pelo próprio estudante que realiza o teste, o que pode ser um fator limitador importante na produção de informações sobre os níveis de alfabetização dos estudantes, uma vez que, para conseguir realizar o teste, eles devem ter alcançado um nível de leitura que lhes permita ler e interpretar os enunciados. Esse fator é especialmente relevante à análise do desempenho em matemática, uma vez que o estudante pode errar um item que avalie um determinado conhecimento matemático por não ter desenvolvido as habilidades de leitura necessárias à compreensão do enunciado que apresenta a tarefa a ser realizada. Considerando o exposto, é possível afirmar que a ANA produz informações sobre produtos da alfabetização, e não sobre os processos que levam a essa alfabetização. Esses processos devem ser acompanhados pelos docentes a partir das atividades e instrumentos de acompanhamento e registro das aprendizagens, sugeridos nos documentos de formação do Pacto e abordados na primeira seção deste artigo. Além disso, é importante lembrar que a ANA é realizada ao término do $3^{\circ}$ ano do bloco pedagógico, 
havendo, portanto, a necessidade de que os professores reflitam e discutam sobre como as habilidades que ela avalia são objeto de intervenções sistemáticas ao longo de todos os anos do bloco.

Finalmente é importante lembrar que nas avaliações em larga escala a validade do teste e de seus resultados é estabelecida com base em critérios psicométricos ${ }^{4}$ a partir dos quais é possível compreender se os itens realmente estão avaliando o que se propõem a avaliar e se o teste, em seu conjunto, está adequado ao público a que se destina, por exemplo, contemplando itens com diferentes níveis de dificuldade, de modo que seja possível captar diferentes desempenhos possíveis entre os estudantes que realizam o teste. Entretanto, Fernandes (2009) alerta para a importância de que sejam considerados, para além dos critérios psicométricos, outros fatores que podem concorrer para a validade de um teste. Citando Gipps (1994), o referido autor afirma que "a validade é hoje encarada como um conceito unitário em que o constructo (a competência ou a aprendizagem subjacente) é o tema unificador (FERNANDES, 2009, p. 133). Nesse sentido o conceito de validade extrapola os limites estritos do teste e passa a abarcar as interpretações que dele se fazem com relação às aprendizagens dos estudantes e às condições de produção dessas aprendizagens e o modo como essas interpretações subsidiam novas intervenções. O que está em jogo com a aplicação das avaliações em larga escala, neste caso, não é apenas a eficácia dos instrumentos para medirem o que se propõe, mas as dimensões ética e social envolvidas no próprio ato de medir, ou seja, na capacidade de se oferecer respostas às questões que os resultados dessas avaliações nos apontam.

\section{Considerações Finais}

Como busquei evidenciar ao longo deste texto, as

A psicometria se refere ao uso de medidas em Psicologia, se propõe a estudar os fenômenos psicológicos a partir de sua mensuração.
A avaliação no âmbito do Pacto Nacional pela Alfabetização na Idade Certa 
ações do Pacto Nacional pela Alfabetização na Idade Certa oferecem uma ótima oportunidade para um aprofundamento do debate sobre o papel da avaliação, não apenas na alfabetização, mas na educação, de modo geral. Vista no passado como instrumento de classificação e penalização dos estudantes, contemporaneamente corremos o risco de concebê-la como panaceia capaz de solucionar todos os problemas da educação. Ambas as perspectivas são equivocadas. Para que a avaliação possa efetivamente contribuir para uma melhoria da qualidade da educação é necessário ter clareza sobre o que se pretende avaliar, esforço intelectual para se compreender o que é possível ser avaliado e, principalmente, o que é preciso fazer com os resultados que obtemos a partir do que é possível avaliar.

\section{REFERÊNCIAS}

BRASIL. MEC/CNE/CEB. Resolução n ${ }^{\circ} 7$ de 14 de dezembro de 2010. Fixa as Diretrizes para o Ensino Fundamental de 9 anos.

BRASIL/ MEC/SEB. Pacto Nacional pela Alfabetização na Idade Certa. Avaliação no Ciclo de Alfabetização: reflexões e sugestões. Brasília: 2012.

BRASIL/INEP. Avalição Nacional da Alfabetização: documento base. Brasília, 2013.

CHARLOT, Bernard. Da relação com o saber: elementos para uma teoria. Porto Alegre: ARTMED Editora, 2000.

FERNANDES, Domingos. Avaliar para aprender: fundamentos, práticas e políticas. São Paulo: Editora UNESPE, 2009.

FRANCO, Creso. Quais as contribuições da avaliação para as politicas educacionais? In: BONAMIN, Alícia; FRANCO, Creso; BESSA, Nícia (orgs.) Avaliação da Educação Básica: pesquisa e gestão. Rio de Janeiro: Editora PUCO-Rio; São Paulo: Edições Loyola, 2004, p. 45-63. 
HOFFMANN, Jussara. O jogo do contrário em avaliação. Porto Alegre: Editora Mediação, 2007.

NÓVOA, Antônio. Apresentação. In: FERNANDES, Domingos. Avaliar para aprender: fundamentos, práticas e políticas. São Paulo: Editora UNESPE, 2009.

\section{Assessment under the National Pact for Literacy at The Right Age}

\section{Abstract}

This article is addressed assessment under the Pacto $\mathrm{Na}$ cional pela Alfabetização na Idade Certa-PNAIC. In the first section of the text discusses the guidance on internal assessment to school, training offered by the Pacto materials, with emphasis on the procedural dimension and the necessary involvement of the different actors of the educational scene with assessment practices. The second section is addressed to external evaluation to school, the Avaliação Nacional da Alfabetização-ANA - established as part of the actions of the Pacto. Presents the principles that underlie this assessment, the instruments used to effect it and its limits and possibilities. The concept of validity of the tests used in large-scale assessments is questioned in this second section, seeking to extend it to think beyond the psychometric validity, the validity of conducting the evaluation itself, directly related to the modes of appropriation of their results.

Keywords: Literacy. Evaluation. PNAIC.

Data de recebimento: agosto 2014

Data de aceite: setembro 2014
A avaliação no âmbito do Pacto Nacional pela Alfabetização na Idade Certa 